\title{
TRAJETÓRIAS DAS JUVENTUDES POPULARES - VIDAS MAMBEMBES QUE SE RESIGNIFICAM EM SEUS COTIDIANOS
}

\author{
Noelia Rordrigues Pereira Rego \\ Universidade Federal do Estado do Rio de Janeiro (UNIRIO), RJ, Brasil
}

\begin{abstract}
Resumo: As análises deste estudo antropológico revelam, em diálogo constante com outras pesquisas relacionadas ao trabalho e à educação, as incertezas da sociedade atual, as formas diluídas das organizações produtivas de atividade humana no âmbito de uma sociedade regida pelo capital, dentre outros elementos que subjazem ao que podemos chamar de trajetórias mambembes de possibilidades, acesso e ascensão. Em nosso caso, trata-se das juventudes populares estudantes de EJA - Educação de Jovens e Adultos, com trabalhos precarizados. Ressalta-se ainda a importância do associativismo dessas juventudes, por meio de coletivos e movimentos sociais, como forma de resistência e de sobrevivência social e, principalmente, física, no bojo de uma sociedade marcada pelas mais intensas e perversas desigualdades.
\end{abstract}

Palavras-chave: Juventudes. Trabalho. Educação. Movimentos Sociais.

\section{INTRODUÇÃO}

A categoria juventude enquanto pauta de pesquisas é muito recente e vem a cada ano tomando lugar em centros de investigação - criados especialmente para a categoria - territórios e movimentos sociais nos seus mais variados matizes. As pesquisas com as juventudes relacionadas ao campo da educação e do trabalho, em conjunto, têm início na década de 70 . No entanto, é na década seguinte que os estudos que buscam traçar uma identidade juvenil a partir de seus processos de estudo e trabalho se consolidam (MADEIRA, 1986). Muito embora a temática não seja recente, é no século XXI que ela toma corpo e forma mais delineada principalmente na América Latina.

As juventudes como campo de investigação adquirem cada vez mais adeptos em diversas áreas do conhecimento e a construção de base de dados é tarefa que compromete muitos centros de estudos. No entanto, um número cada vez maior de jovens, sobretudo universitários e militantes de favelas e periferias, tem tomado para si a alcunha e o leme de pesquisa sobre seus pares, e o chamado "Nós por Nós" tem se tornado realidade nesses novos horizontes de investigação que se firmam, dando assim aos dados quantitativos "duros" e "frios" a devida consistência e legitimidade.

É na década de 1990, como apontam Corrochano e Nakano (2009), que questões sobre as juventudes relacionadas à escola e ao trabalho ganham visibilidade. A saída da escola e as formas de inserção dessas juventudes no mercado de trabalho, bem como o 
desemprego, também serão fatores de importância para as esferas públicas e para as análises de muitos pesquisadores que se debruçam em compreender o cotidiano dessa população e suas relações, especialmente com estas duas categorias.

É assim que no contexto de uma ainda embrionária globalização no século XX que a categoria juventude tem início e abertura. A cultura pop, a cultura de resistência e a contracultura das décadas anteriores anunciaram aquilo que tempos depois se tornaria a cultura de massa. É dentro deste cenário que o conceito de juventude toma sua estrutura no universo capitalista. Ombro a ombro a essas transformações vem também o estímulo forte e tenaz ao consumo, que como um efeito cascata trará a facilidade de crédito, seguido da liquidez e flexibilização do dinheiro, culminando no endividamento das classes trabalhadoras, que trabalham para pagar dívidas e a continuarem na roda viva do ciclo consumista.

Nossas análises de pesquisa muito se assemelham com as de Foote Whyte (2005) e suas análises sobre Corneville quando se opunha à perspectiva da classe média branca norte-americana - que concebia todas as áreas pobres e sua população como caóticas e débeis - abrindo a escuta e a percepção para os "de dentro", que "vêm em Cornerville um sistema social altamente organizado e integrado" (p. 21). Assim, nosso trabalho toma partida e partido por meio de uma análise de campo em que o que está em jogo é a perspectiva vinda da(o)s jovens, para a(o)s jovens e com a(o)s jovens das classes populares, que um sem-número de vezes são objetificados pela sociedade que vê neles uma geração perdida, bem como sua atuação no meio social por vezes menor e/ou insignificante.

É no terreno das incertezas que essas juventudes irão se aventurar em suas trajetórias de múltiplas e alinhavadas realidades construídas diariamente na busca constante por sobrevivência. É por meio de seus modos de se fazer existir que muitas vezes essas juventudes se territorializam e afirmam suas identidades, contracultura e resistência, por meio de suas culturas próprias e processos de elaboração de realidades e saberes. Movimentos que trarão o protagonismo e, sobretudo, o entender-se enquanto sujeito de sua própria história, procurando reivindicar direitos e fomentar políticas públicas a partir de suas demandas e anseios.

\section{1- CONSTANTES INCERTEZAS E INSTABILIDADE NOS POSTOS DE TRABALHO}

O sociólogo brasileiro Ricardo Antunes concebe o capitalismo como um sistema tridimensional, pois envolve capital, trabalho e estado. Assim, este sistema se alimenta e se reproduz daquilo que é produzido pelo trabalho e sua força, neste último caso, o trabalhador. A centralidade do trabalho e sua importância para a permanência da sociedade é, segundo o autor, um elemento ontologicamente essencial e fundante da existência, da vivência e da permanência humana (ANTUNES, 2010). Antunes analisa de forma minuciosa a configuração da classe trabalhadora e as nuanças que a envolvem: trabalho produtivo-improdutivo, material-imaterial, uma vez que o capital necessita do trabalho vivo para se reproduzir. $\mathrm{O}$ autor ainda discorda da ideia de que a classe trabalhadora está no fim, como pensam alguns teóricos como André Gorz (1982) por 
exemplo, e explica que a reestruturação reprodutiva do trabalho faz parte de uma "dimensão fenomênica" pautada pela crise do taylorismo-fordismo e o nascimento do toytismo e das políticas neoliberais. Essa reestruturação produtiva é a própria reinvenção endógena do capital para manter-se vivo.

A Classe-que-vive-do-trabalho, essa polissêmica e multifacetada classe trabalhadora é alvo dessas reinvenções que incluem em sua lista a multifuncionalidade do trabalho, a equipe e as células de produção, por exemplo. Controlar a subjetividade do trabalhador e da trabalhadora é tarefa dessas reinvenções que se travestem de cooperação e de comprometimento, mas que nada mais são que estratégias de manipulação alienante do trabalho estranhado: "Quer pelo exercício laborativo manual, quer pelo imaterial, ambos, entretanto, controlados pelo sistema de metabolismo societal do capital, o estranhamento (Entfremdung) do trabalho encontra-se, em sua essência, preservado" (ANTUNES, 2013, p. 132).

As intensas mudanças no cenário mundial na década de 1980, especialmente com a crise do sistema-mundo (WALLERSTEIN, 2007) se solidificando e tornando o capital flexível já no início dos 1990, fez com que profundas reconfigurações atingissem o mundo do trabalho provocando demissões e constante desemprego, sobretudo, dadas essas condições, a postergação, mesmo que compulsória, do chamado "primeiro emprego" para os jovens. Dentro deste contexto, Robert Castel (1998) nos chama atenção para as novas questões sociais que vão surgindo, e nos traz ainda a noção de "interino permanente", categoria que tem como marca empregos com frágeis vínculos e tempos curtos, com baixos salários, e que tem como protagonistas, mormente, as juventudes pobres.

A participação juvenil no mercado de trabalho no ano de 1980, segundo o IBGE (1991) - Instituto Brasileiro de Geografia e Estatística - era superior a 40\%. Desse modo, o Brasil se destacava como o país com uma considerável participação jovem no mercado de trabalho. Mas que tipo de inserção seria essa? Ainda assim, o Brasil enfrentava graves problemas de desemprego nessa época, e na década de 90 isso se intensificará muito por conta das mudanças ocorridas na esfera econômica mundial que atingirão de forma direta as searas do trabalho e, ainda, da educação, como acima comentamos. Nessa década, o desemprego no âmbito das juventudes chega a patamares consideráveis, quando $60 \%$ dos desocupados no país eram jovens: do total de 7.838 .218 milhões de trabalhadores desocupados no Brasil no final desta década, segundo a Pesquisa Nacional por Amostra de Domicílio (PNAD, 1999), 4.755.135 milhões eram jovens. Pochmann (2004) nos sinaliza um duplo movimento para esta época: enquanto houve o aumento da População Economicamente Ativa (PEA) para 1,3 milhões de pessoas, ao seu lado houve também a redução da ocupação para as juventudes: a ocupação decaiu em 448 mil postos de trabalho.

Mesmo assim, é tão somente nos momentos finais da década de 90 e primeiros anos dos 2000 que políticas em torno das juventudes começam a ser timidamente pensadas. Muito ainda embrionárias, tais desenhos políticos ainda não davam conta da diversidade que compõem as juventudes. Assim, tínhamos um viés de ações emergenciais e estereotipadas no lugar de políticas de fato congruentes e reparatórias em sua essência. Chegando aos anos 2000, conforme observa Graça Druck (2011) e Ricardo Antunes (2013), constatamos a entrada das terceirizações e outras iniciativas 
tomando a cena no campo trabalhista de forma a flexibilizar e precarizar ainda mais trabalhadoras e trabalhadores em suas mais diversas atividades laborais.

A substituição do trabalho contratado e regulamentado, dominante no século XX e sua substituição pelas modalidades atípicas de trabalho, como o "empreendedorismo", "cooperativismo", "trabalho voluntário", etc., cada vez mais parecem se configurar como formas ocultas de trabalho que permitem aumentar ainda mais as distintas formas de flexibilização salarial, de horário, funcional ou organizativa (ANTUNES, p. 51, 2013a).

Dentro do contexto latino-americano, o Brasil traz em seu bojo marcas de um processo de modernização e desenvolvimento socioeconômico com consideráveis margens de desigualdade econômica e regional ${ }^{2}$. Assim, ao analisarmos os processos de inserção das juventudes nos postos de trabalho, torna-se impossível a não concatenação dessas questões que marcam a composição do país enquanto estado-nação. Foi assim que, historicamente, a "libertação" significou parcas locomoções e espacialidades na esfera social, logo econômica, para as populações tradicionais, para os negros e sua descendência. De acordo com Mello e Novais (2009), a consolidação desse modelo de modernização e desenvolvimento teve no Golpe Empresarial-Militar de 1964 seu maior apelo difusor, tendo produzido ao longo de seus vinte e um anos de vigência uma sociedade deformada e timocrática. $O$ que se testemunhou de fato foi o aumento alarmante dos indicadores de pobreza, analfabetismo, mortalidade infantil, por exemplo, tendo a elevação da desigualdade social por meio de um acelerado e irresponsável crescimento econômico, que beneficiou tão somente as classes abastadas, conjuntura que Tavares e Assis (1985) denominam "modernização conservadora".

\section{2 - JUVENTUDES E SUAS VIDAS MAMBEMBES - BUSCANDO "SEU LUGAR AO SOL"}

No sistema capitalista há uma drástica dicotomia entre as exigências de qualificações e diplomas versus a redução de postos de trabalho e oportunidades de emprego. Desse modo, a demanda por sobrevivência no mundo do capital, sobrevivência esta social mas sobretudo física, principalmente das juventudes - e com um recorte mais aprofundado das juventudes populares e negras, inclusive -, irá demandar o que nós vamos denominar aqui de vida mambembe, que é o improviso e a busca cotidiana de bicos e outras atividades consideradas fora da esfera trabalhista formal em que "a gente recebe na mão, limpo", ou seja, sem descontos formais, tentando driblar as diversas e perversas desigualdades, o que garantirá a sobrevivência imediata desta população.

A pesquisa Perfil da Juventude Brasileira (2003) constata que as juventudes possuem relações de intensa preocupação com o futuro, sobretudo em questões relacionadas ao emprego, com especial destaque para os jovens de baixa renda, grupo no qual se incluem negros e negras e moradoras/es de periferias, que vivenciam a exclusão social desde as suas origens. Lado a lado com o trabalho, a educação ocupa papel central na vida de muitos desses jovens. No entanto, a famigerada meritocracia vem a reboque e se impõe como condição de maior ou menor esforço para essas juventudes que se veem 
compelidas a responsabilidades que não estão ao seu alcance, pois partem de searas econômicas e políticas desiguais, relacionadas à situação do país em determinados períodos histórico-econômicos. Atrelado a isso, o histórico projeto de precarização da escolarização pública aponta para as juventudes populares, universo de possibilidades nessa fase da vida, pois passam desde muito cedo por intensas privações de acesso a equipamentos, instalações físicas, propostas educativas diferenciadas, em que estão aí imbricadas a formação de professores e políticas de financiamento.

Como vive esta geração juvenil que segue estigmatizada, infantilizada e inferiorizada principalmente pelas instituições? Como se dão suas experiências por vezes mambembes para encarar esses preconceitos complexos e com múltiplas ações de forma a legitimarem docilmente as desigualdades a que são submetidos?

As iniquidades vividas e sentidas no seio destas juventudes, mambembes que são, nos confirmam que estamos longe de termos uma democracia de fato verdadeira. Nos dados do Ministério da Saúde, por exemplo, por meio do Mapa da Violência (WAISELFISZ, 2013), vemos que a taxa de homicídios de jovens negros é duas vezes maior do que a do restante da população jovem. Isso revela talvez o maior problema entre as juventudes: a condição primeira de existir e quando existir: (re) existir dentro de um sistema perverso e desigual. Na pesquisa Agenda Juventude Brasil (2013), 54\% dos jovens pesquisados afirmaram terem perdido um jovem negro entre seus pares. Em nossa pesquisa, $77 \%$ respoderam a mesma questão.

Por mambembe o reconhecido e prestigiado dicionário Aurélio entende ser, dentre outras definições: "grupo de teatro amador e de má qualidade". No entanto, diferindo dessa definição, mambembe em nosso caso se entende como diversos modos de "sobrevivência", nos improvisos que essas juventudes populares têm de realizar diariamente aqui e ali para conciliar estudo e trabalho, e ainda numa série de obrigações sociais (cônjuge, filhos, religião, etc) que têm de dar conta (e com êxito, diga-se), sem espaço e possibilidade para a má qualidade em suas ações cotidianas. Seria também o que entendem Charlot e Glasman (1998) por um "verdadeiro caminho de combates", a tensão constante entre trabalho e escola. E ainda, a juventude da "viração", como apresenta Faleiros (2008), que busca o tempo todo novas formas de sobrevivência numa sociedade de incertezas e riscos (BECK, 2000). Já mesmo na década de 1980, Felícia Madeira apontava as intervaladas nos processos de escolarização juvenil. Constata-se assim que não se trata de um movimento novo, mas que esses "vai e vens", essa vida mambembe que aqui denominamos, caminham com as juventudes populares marcando suas trajetórias desde muito tempo.

No Brasil, é na última década do século XX, que novas bases educacionais são formuladas de forma a trazer diretrizes e adequações da força de trabalho com as novas formas de modelo de trabalhador, de maneira a "promover a transição entre escola e o mundo do trabalho, capacitando jovens e adultos com conhecimentos e habilidades gerais e específicos para o exercício de atividades produtivas" (LDB, 1996). Assim, "a relação trabalho e a educação passam a ser expostas de forma ardilosa e sutil, e aparece como direito dentro de uma igualdade abstrata" (FRIGOTTO, 1989, p. 15). É essa "igualdade abstrata", à qual se refere o autor, que vai trazer e confirmar possibilidades para alguns e inúmeras barreiras para tantos outros. 
Para Dauster (1992) o trabalho nas camadas populares é visto como status, muito mais que a educação escolar. Sem correr o perigo das generalizações, concordamos com suas análises no que tange ao nosso universo vivido e pesquisado durante quase uma década de investigação de juventudes de matriz popular da Cidade do Rio de Janeiro. Para tanto, dentro de tais composições familiares e vicinais, as condições laborais estariam em primeiro plano, tornando-se um símbolo de status, que difere o jovem-trabalhador do jovem que não quer nada com o trabalho. Portanto, é no plano ideológico e cultural que pode estar a chave para se entender a adesão à cultura do trabalho como status social, visibilidade, e por isso, pertencimento.

Fato é que o trabalho para essas juventudes é a porta de entrada para o mundo social, para existir, para pertencer dentro de seus espaços de sociabilidade. Por isso, por vezes de forma mambembe, de improviso, como forma de "se virar", esses jovens se sujeitam a trabalhos precarizados, informais ou mesmo formais por curtos períodos de tempo, muitas vezes abandonando os estudos dada a carga horária pesada que são obrigados a enfrentar, mesmo tentando, ainda que sem sucesso, a dobradinha trabalhoescola.

\section{3 - DESDOBRAMENTOS DA PESQUISA}

Discorrendo sobre questões vitais, refletindo com muita propriedade as variáveis complexas que compõem o mundo do trabalho de uma juventude historicamente em desvantagem, Machado Pais (2001) nos oferece, a partir de suas pesquisas com jovens trabalhadores, inúmeras leituras sobre suas vivências e experiências laborais. Comungando com as questões de Pais (2001) percebemos que o lugar significante da categoria trabalho vem sendo redefinido. $O$ que antes era visto como profissionalização e mesmo um rito de passagem: "a responsabilidade", a perspectiva da viração e da luta pelo "pão de cada dia" - que para o autor seriam tachos - tais fatores hoje têm sido determinantes no cotidiano desses jovens que se sujeitam a pluriempregos temporários e mesmo ilegais para garantia de sobrevivência. Os "ganchos" a que o autor também se refere e que conhecemos no Brasil pelos "bicos", nos trazem a dimensão do nível de precariedade laboral a que as juventudes estão expostas.

Em nosso trabalho, procurando aprofundar ainda mais as análises sobre as juventudes, procuramos empreender diagnósticos sociais e seus significados e significantes políticos sobre suas demandas, de modo a nos depararmos com as causas estruturais às quais se defrontam as juventudes populares contemporâneas. $\mathrm{O}$ que para Pais (2001) seria um "dilema de labirinto", para nós seriam as trajetórias mambembes que se mostram no curso de vida desses e dessas jovens e que delineiam muito, senão o todo, do porvir de suas vidas. Diferentemente do que acontece com as juventudes de classe média, para as juventudes de origem popular não se trata de uma transição linear, esperada, tampouco previsível, mas cada dia se constitui como uma batalha a ser vencida, onde os imprevistos aparecem de forma contumaz: "para estes jovens, um novo dia representa uma nova partida, um novo jogo" (PAIS, 2001, p. 57). "Interpretar um relato de 
vida não é dar-lhe um sentido de linearidade mais ou menos fundamentado, mas apreciar a pluralidade de que a vida é feita"(PAIS, 2004, p. 85).

Tornando-se impossível falar de seus percursos laborais sem atrelarmos às conexões familiares, escola e redes de contato, constatamos que em sua maioria as improvisadas e descontínuas trajetórias desses jovens são construídas num universo de escassas possibilidades, em principal pelo seu contexto socioeconômico. Gradativamente elas vão tomando formas, delineando suas histórias de vida pouco a pouco e de maneira bastante imprevisível, por isso mambembe. Todavia, "seus projetos são guiados, no entanto, por uma certeza: ninguém pode ficar parado", pois "é o movimento, em sua ampla gama de significados e em todos os sentidos e direções, que conduz à estratégia para conseguirem realizar seus sonhos" (MAIA e MANCEBO, 2010, p. 15). Pautados, por vezes, pela ideologia neoliberal de sucesso, que tem no mérito pessoal individual sua marca para a promoção da competitividade, algumas juventudes passam a integrar suas possibilidades de vida de acordo com esse ideário que, como uma segunda pele, passam a fazer parte de suas práticas cotidianas de se relacionar, de seus gostos e da tessitura de sua constituição como indivíduo.

$\mathrm{Na}$ atualidade, temos visto inúmeros trabalhos e categorias criadas em torno das juventudes relacionadas aos seus processos de entrada, saída e permanência no mercado de trabalho. Importante dar espaço em nossas análises para aquilo que convencionou-se chamar de "nem, nem" e "nem aí". A primeira categoria seriam jovens que nem estudam, nem trabalham e a última seria destinada aos jovens que não estão procurando trabalho e nem estudando. Diferente daquilo que mais acima denominamos jovem-trabalhador/ jovem que não quer nada com o trabalho, categorias que apreendemos em nossa pesquisa de mestrado por meio dos relatos orais dos próprios participantes, as categorias "nem nem" e "nem aí", têm sido veiculadas na mídia corporativa de forma híbrida e tendenciosa, alegando anomia e desinteresse de toda uma geração de jovens, por vezes a produzir possivelmente ainda mais estigmas sobre uma juventude com cor, classe e região de moradia definidos.

Dentro da pesquisa Agenda Juventude Brasil (2013), a categoria "nem, nem" ficou na escala dos $20 \%$ para jovens pobres, contra $2 \%$ para jovens da classe média. Fato que, para além de inúmeros questionamentos pois essa juventude tem nas atividades informais muitas vezes seu "ganha-pão" cotidiano, nos mostra a necessidade primordial de políticas públicas que possibilitem a construção de trajetórias dignas e equânimes, pois "La inequidad o desigualdad surge cuando existen diferencias sistemáticas en los resultados que obtienen los sujetos que parten de distintas posiciones en la estructura social" (FILARDO, 2010, p. 06).

Fazer com que esses jovens tenham o protagonismo, Ihes abrindo a possibilidade e principalmente o direito de escolha e participação na esfera pública, requer qualidade e equidade na escolarização e ainda postos de trabalho decentes. Essa via se dá sem dúvidas por intermédio de políticas públicas e ações afirmativas que de fato vejam a juventude como um campo de possibilidades, de expansão, e não como um campo minado, que se deve aglutiná-lo por receio de pôr à prova a ordem social vigente, pois, "quando se trata de jovens pobres, ainda mais se forem negros, há uma vinculação à ideia do risco e da violência, tornando-os uma 'classe perigosa'" (DAYRELL, 2007, p. 1117). 


\section{4 -ALGUMAS CONSIDERAÇÕES SOBRE COLETIVIZAÇÃO E MOVIMENTOS SOCIAIS NO ÂMBITO DAS JUVENTUDES POPULARES}

Os movimentos de 1960 no Brasil e no mundo tornaram as juventudes protagonistas, sobretudo de classe média. Nascidos no contexto da segunda grande guerra, abarcados que foram pelas ditaduras militares, especificamente na América Latina, passa-se a dar maior atenção a estudos sociológicos, sob diversos aspectos, sobre essa camada da população. Um bom exemplo disso é: "A juventude na sociedade moderna", de Marialice Foracchi (1972). Tornado um clássico, a autora questiona e contextualiza a "rebelião da juventude na sociedade moderna", sob o prisma do movimento estudantil. Nos dias atuais o movimento estudantil institucionalizado, embora ainda atuante em alguns aspectos não nos chama tanto a atenção quanto os movimentos de articulação de jovens moradores e moradoras de favelas e periferias. Isto porque embora tenhamos bons avanços nas questões de expansão do ensino superior, por exemplo, a grande maioria das universidades, principalmente em cursos específicos continua destinada às elites e sutilmente desqualifica, e por vezes interdita, quem vem dos setores populares.

Fato é que as juventudes de hoje, cujo recorte analítico já temos definido, é sobremaneira mais articulada em redes que as juventudes populares de outrora. Temos visto inúmeros coletivos nascerem no intuito de cobrarem demandas específicas, bem como de denunciarem diversas formas de violência (física ou simbólica) a que estão submetidos diariamente, procurando equalizar e tornar reais seus anseios e aspirações. Coletivos jovens de moradoras e moradores de favelas e periferias têm se formado e se multiplicado, indo da cultura para questões de gênero, passando pelas demais questões relativas a direitos, esses coletivos têm se tornado significativos no processo de construção de cidadania para o segmento. Seja ainda dentro de grêmios estudantis, que até bem pouco tempo estavam praticamente extintos ou se transformaram em braços das direções das escolas, seja dentro do ambiente acadêmico, vimos inúmeros coletivos de estudantes populares se tornarem imensamente atuantes também nestes espaços, sobretudo a partir das manifestações ocorridas no país em 2013.

O sentido de percurso ocupacional constitui uma dimensão-chave para compreender as lógicas de ação e também da diferenciação das formas de identidade. Assim, as diferentes formas de trajetórias valorizadas pelos trabalhadores associam-se às tentativas de construção de suas formas de identidade em busca de reconhecimento (VIEIRA, 2007, p. 13).

São as lutas sociais que, segundo Antunes (2010), trarão gradativamente a emancipação humana, denunciando a lógica destrutiva do capital através da rebeldia da heterogênea e complexa classe trabalhadora que, apesar dessas características, tem se associado de diversas formas - movimento feminista, movimento negro, LGBTTIQ, movimento ecológico, movimentos de favelas e periferias, movimentos de reivindicação de terras e teto, movimentos de educação popular e tantos outros -, muitos deles vinculados entre si, onde adquirem fôlego e vigor no chão de suas lutas. O papel histórico 
das lutas sociais em prol de melhores condições de trabalho e emancipação humana tem importância fundamental nas conquistas em que hoje nos ancoramos. Apesar de todos os ataques aos nossos direitos recebidos ao longo do século XX, Ricardo Antunes (2010) coloca a legalidade de tais lutas, salientando que a condição de rebeldia é extremamente necessária numa sociedade regida pela mercadoria.

\section{CONSIDERAÇÕES FINAIS}

Os jovens demoram mais para sair da escola, mas em relação à entrada no mercado de trabalho, a variação é menos expressiva. A juventude brasileira é uma juventude trabalhadora (CORROCHANO, 2013, p. 29).

Numa sociedade onde a sensação de fracasso é frequente e permanentemente nutrida, a capacidade de associação é cada vez mais requerida como forma de resistência e de descolonização de práticas consideradas "necessárias ao desenvolvimento". Fazer o movimento contrário talvez seja a possibilidade e a saída que, com outras palavras, nos aponta Richard Sennet (1999), por meio do combate a estas novas e não menos perversas formas de capitalismo:

O pronome "nós" é um perigo gigantesco para os capitalistas que vivem da desordem da economia e temem a organização e o ressurgimento dos sindicatos (...) um regime que não oferece aos seres humanos motivos para ligarem uns para os outros não pode preservar sua legitimidade por muito tempo (SENNETT, 1999, p.176).

Uma das chaves para se abrir a dialética a um pensamento outro, descolonizado portanto, poderia estar numa pequena provocação de Homi Bhabha (1998, p. 243), que diz: "precisaremos repensar os termos através dos quais concebemos a comunidade, a cidadania, a nacionalidade e a ética da afiliação social?". Diria eu que sim. E os desdobramentos da resposta a esta indagação podem dizer muito do que nós somos e de que lado estamos.

Segundo Sennett (1999), o capitalismo vive um novo cenário marcado por uma flexibilidade tomada como natural, que de certa maneira vai de encontro às tradicionais formas de trabalho e seus significados construídos historicamente. Novos contornos são dados, novos sentidos e significados também, em torno da temática. As incertezas somadas às ansiedades de não saber o que os/as espera darão o tom desse "novo" lugarcomum das práticas de trabalho. Novos elementos se somam nessa esfera, dentre os quais um certo senso de ética dada a competitividade que se cria em torno da categoria que põe em xeque a própria noção de caráter. O capitalismo mundializado e legitimado como única saída afeta, como um todo, relações que antes se pautavam na esfera da solidariedade e alteridade, criando relações de animosidades diversas nessa "corrida pelo ouro". Essa incerteza, que não garante mais, de certa forma, condições lineares de vida é que vai reger as relações entre indivíduos. A nova lógica instaurada, que não prevê longo prazo, não prevê também que a permanência, pautada pela qualidade nas práticas trabalhistas, é uma forma de dar sentido ao trabalho e promover laços entre trabalhadores. 
Por outro lado, mesmo com uma rápida análise de conjuntura, por meio de dados estatísticos oficiais, etnografia, entrevista e observação, verifica-se que os trânsitos de vida das juventudes não são lineares, tendo destaque aí para as juventudes populares. Pesquisar e investigar de forma mais aprofundada algumas trajetórias juvenis pode, sem dúvida, mostrar um pouco do que se passa com a sociedade como um todo, pois ela sendo espelho retrovisor da sociedade (NOVAES, 2007), está sempre sendo tocada em questões que envolvem diversos setores de diversas esferas sociais, exposta às configurações e reconfigurações porque passa o mundo contemporâneo. Assim, "os jovens podem nos informar alguma coisa sobre os vetores e linhas de força que desestabilizam campos sociais prévios, ou os redefinem, deslocam suas fronteiras, abremse para outros e também traçam as linhas que desenham as novas figuras da tragédia social" (TELLES; CABANES, 2006, p. 217).

Se o trabalho constrói a juventude como afirma Marilia Sposito (2005), montar, construir, dialogar e analisar 21 singulares trajetórias juvenis em torno da categoria nos traz a noção do quanto podem ter em comum tais percursos de vida, que se inclinam e se debruçam em casos semelhantes na América Latina. Em outras palavras, dentro dessa configuração de vidas variadas, regidas em torno de algo comum como o trabalho e a educação, pode estar a pista para muitas assertivas em torno de uma ideologia de viver em sociedade que se configurou e se perpetuou historicamente em países de periferia como o Brasil, trazendo consigo importantes estratégias de disciplinarização intelectual, sobretudo. A lógica das competências que estão presentes na teoria do capital humano e hoje no campo das formações é um bom exemplo disso (FRIGOTTO, 2009).

É muito pelo trabalho que a posição na camada social será definida ao longo da vida, isso porque o trabalho ocupa lugar de centralidade da vida social, pois é combinado a relações simbólicas de poder e status. Assim, as trajetórias no universo trabalhista vão compor em grande medida aquilo que se convenciona chamar de "sucesso" ou "fracasso" profissional-pessoal. Por sua vez, o duelo entre estudo e trabalho se intensifica ainda mais para aqueles que não têm qualquer possibilidade de se firmar em nenhum dos dois. Em se tratando de escolarização, as maiores dificuldades estão na informação e no acesso dessas juventudes, que frequentemente abortam os estudos em prol do ganha-pão imediato. A violência da competitividade é outra barreira que estrutura e fundamenta suas lógicas particulares de trajetórias mambembes e que têm de enfrentar no mundo do capitalismo mundializado. Isso em se tratando somente dessa dualidade trabalho $\mathrm{x}$ escola, se formos falar das barreiras de acesso na busca pelo ensino superior, se torna muito mais evidente essa violência estrutural, sobretudo para as camadas juvenis mais pobres, de quem aqui tratamos.

Consoante às suas necessidades, essas juventudes têm de tornar suas vidas mambembes para darem conta muita das vezes do sustento da própria família, como é o caso de Regina, 23 anos, mãe de 3 filhos: "Meu filho de 9, toma conta dos dois menores de 5 e de 3. Eles estudam na mesma escola e no mesmo horário, aí fica mais fácil pro Binbin cuidar deles. Eu faço faxina em dias alternados, quando não estou na faxina faço unha no salão no pé do morro onde eu moro e passo roupa também na casa das pessoas. E ainda tô tirando meu diploma esse ano. Graças a Deus!". 
De acordo com as trajetórias estudadas percebemos de início que há, sim, um esforço na esperança por conciliar estudo e trabalho. Contudo, no decorrer do cotidiano, questões relativas ao cuidado com a família, à constante necessidade de hora-extra, mesmo que compulsória e a escola ainda com dificuldades em entender essas lógicas particulares são elementos decisivos para que ela, a própria escola, se torne preterida neste processo, quando ouvimos relatos do tipo: "saí da escola, pois chegava atrasado e ainda tomava esporro e o professor não deixava entrar. Tá de sacanagem, né? Tinha que dar graças a Deus que eu consegui chegar!" (Cleilson, 25 anos).

Assim, é preciso que a escola entenda esse jovem que abandona os estudos e retorna em uma fase mais madura de sua vida para construir novas pontes com saberes outros, porque vem com novas perspectivas. É, neste sentido, que ampliar a escuta para trabalhar com suas bagagens de vida e demandas se faz necessário para que novamente o êxodo escolar não se configure, mas ao contrário, que neste novo momento de sua vida a escola, em conjunto com esse aluno da EJA possam caminhar juntos em novas perspectivas de ampliação de pensamento e realidades. É ainda persistir num currículo efetivamente democrático e plural, permeado de experiências, sonhos e projetos. Acredito que seja este também o desafio a enfrentar no campo das políticas públicas, bem como no campo dos estudos sobre juventudes, educação e trabalho.

Estruturalmente, por sua condição à margem dos valores consagrados dentro de uma sociedade capitalista, o ingresso no mercado formal de trabalho, mesmo que de forma precária, é visto como um passaporte para o pertencimento a esferas dessa sociedade. Nesse sentido, abrir uma conta no banco e ter sua carteira assinada "com todos os meus direitos" passam a dar identidade e identificação social a esse jovem: "antes eu nem existia, se eu morresse eu só tinha era a certidão meRmo. E olhe lá!" (Biro, 24 anos). O "trabalho de verdade" estaria, assim, atrelado a este universo institucional e burocrático.

Numa forma de sociabilidade superior, o trabalho, ao reestruturar o ser social, terá desestruturado o capital. E nesse mesmo trabalho autodeterminado que tornou sem sentido o capital gerará as condições sociais para o florescimento de uma subjetividade autêntica e emancipada, dando um novo sentido ao trabalho (ANTUNES, 2010. p. 182).

Fato é que o trabalho para essas juventudes é a porta de entrada para o mundo social, para existir, para pertencer dentro de seus espaços de sociabilidade. Diante disso, as categorias "nem, nem" e "nem ai", às quais anteriormente nos referimos, dentro dessa esfera de realidade e como a grande mídia tem colocado, não se sustenta, bastando uma análise mais profunda e microssocial das realidades de uma juventude historicamente em desvantagem, para termos certeza disso. Por fim, é vivendo nessa sociedade de controle como nos aponta Deleuze (1992), que percebemos o papel fundamental que a escola, o ensino, o currículo e a comunidade escolar exercem no freio e na ativação, na construção e desconstrução deste processo. 


\section{POPULAR YOUTH TRAJECTORIES - MAMBEMBES LIVES THAT RESUME IN THEIR EVERYDAYS}

ABSTRACT: The analysis of this anthropological study reveals, in constant dialogue with other research related to work and education, the uncertainties of present-day society, the diluted forms of productive organizations of human activity within a society governed by capital, among other elements that underlie the Which we can call mambembes trajectories of possibilities, access and ascension. In our case, the popular youth students of EJA - Youth and Adult Education, with precarious work. It is also important to emphasize the importance of the associativism of these youths, through collective and social movements as a form of resistance and survival, social and especially physical, in the midst of a society marked by the most intense and perverse inequalities.

KEYWORDS: Juventudes. Job. Education. Social movements.

\section{CAMINOS DE JUVENTUDES FOLK - VIDAS MAMBEMBES OUE HABITA EN SU REPLANTEAR DIARIO}

RESUMEN: El análisis de este estudio antropológico revela, en constante diálogo con otros trabajos de investigación relacionados con la educación y las incertidumbres de la sociedad actual, las formas se diluyen las organizaciones productivas de la actividad humana en una sociedad gobernada por el capital, entre otros elementos que subyacen en el podemos llamar mambembes trayectorias oportunidades, el acceso y la ascensión. En nuestro caso, los jóvenes estudiantes populares de EJA - EPJA, con empleos precarios. Es de destacar la importancia de la asociación de estos jóvenes, a través de movimientos colectivos y sociales como una forma de resistencia y supervivencia, social y física, principalmente, en medio de una sociedad marcada por las desigualdades más intensos y generalizados.

PALABRAS CLAVES: Jóvenes. Trabajo. Educación. Los movimientos sociales.

Notas:

1) Não nos detemos muito nas análises de Gorz, pois não estaria a discussão sobre a extinção ou não da classe trabalhadora em nossas questões pontuais de investigações neste momento, e muito embora ainda não concordemos com tal perspectiva do autor. Para um aprofundamento maior sobre a temática, ver em: GORZ, André. Adeus ao proletariado: para além do socialismo. Rio de Janeiro, Forense, 1982.

2) Segundo o Programa das Nações Unidas para o Desenvolvimento (PNUD), em 2013, o Brasil estava na quarta posição entre os mais desiguais economicamente da América Latina, estando atrás apenas de Honduras, Bolívia e Colômbia.

\section{REFERÊNCIAS}


ANTUNES, Ricardo. Os sentidos do trabalho. São Paulo: Boitempo, 2010.

Adeus ao trabalho? São Paulo: Cortez, 2013.

BECK, Ulrich. Un Nuevo mundo feliz. Barcelona: Paidós, 2000.

BHABHA, Homi, K. O local da cultura. 3a ed. Tradução de Myriam Ávila, Eliana L. de Lima Reis e Glaucia Renata Gonçalves. Belo Horizonte: Editora da UFMG, 1998.

BRASIL. Lei de Diretrizes e Bases da Educação Nacional. Lei número 9394, 20 de dezembro de 1996.

CASTEL, R. As metamorfoses da questão social: uma crônica do salário. Rio de Janeiro: Ed. Vozes, 1998. 611p.

CORROCHANO, Maria Carla. Jovens trabalhadores: expectativas de acesso ao ensino superior. Avaliação (Campinas) [online]. 2013, vol.18, n.1, pp.23-44. ISSN 1414-4077.

http://dx.doi.org/10.1590/S1414-40772013000100003.

CORROCHANO, Maria Carla; NAKANO, Marilena. Jovens e trabalho. In: SPOSITO, Marilia P. (Org). O estado da arte sobre juventude na pós-graduação brasileira: educação, ciências sociais e serviço social (1999-2006). Belo Horizonte: Argvmentvum, 2009.

DELEUZE, Gilles. Conversações. Rio de Janeiro: Editora 34, 1992.

DRUCK, G. A precarização social do trabalho no Brasil: uma proposta de construção de indicadores. Salvador: CRH/ UFBA/CNPq. Projeto de Pesquisa Bolsa Produtividade do CNPq, 2007/2010 (mimeo).

. O avanço da terceirização do trabalho: principais tendências nos últimos 20 anos no Brasil e na Bahia. Revista Bahia Análise e Dados, Salvador, n.especial, 2011b. (no prelo)

CARDOSO DE MELLO, J. M.; NOVAIS, F. Capitalismo tardio e sociabilidade moderna. Campinas: Edições Facamp; São Paulo: Editora Unesp, 2009.

CHARLOT, B. \& GLASMAN, D. (1998). Introduction. In B. Charlot. \& D. Glasman (dirs.), Les jeunes, I'insertion et l'emploi (pp.11-26). Paris: PUF.

DAUSTER, T. Uma infância de curta duração: trabalho e escola. Cad. Pesq., São Paulo 82: 31- 36, 1992.

DAYRELL, Juarez. A escola "faz" as juventudes? Reflexões em torno da socialização juvenil. Educ. Soc. [online]. 2007, vol.28, n.100, pp. 1105-1128.

FALEIROS, Vicente de Paula: Juventude: trabalho, escola e desigualdade. Revista Educação e Realidade, v.33n. 2, p. 63-82,jul/dez.2008.

FILARDO, Verónica (2010): «Transiciones a la adultez y educación». Cuadernos del UNFPA, Año 4 No5. Montevideo: UNFPA. 
FORACCHI, Marialice Mencarini. A juventude na sociedade moderna. São Paulo: Pioneira, 1972.

FRIGOTTO, Gaudêncio. Educação para a "Inclusão" e a "Empregabilidade" : Promessas que Obscurecem a realidade. In: CANÁRIO, Rui; RUMMERT, Sonia M. Mundos dos Trabalho e Aprendizagem (org). Lisboa: Educa|Autores, 2009. p. 61-77.

(1989). Trabalho, Consciência e a Educação do trabalhador. impasses teóricos e práticos. In: GOMES, C. M.: FRIGOTTO, G. ARRUDA, M.

NOSELLA, P. (org.): Trabalho e Conhecimento: Dilemas na educação do Trabalhador. São Paulo: Cortez.

INSTITUTO BRASILEIRO DE GEOGRAFIA E ESTATÍSTICA. Censo Demográfico 1999/IBGE. Rio de Janeiro, RJ: O instituto, 1991.

\footnotetext{
1999.

Pesquisa Nacional por Amostra de Domicílios - PNAD/IBGE. Rio de Janeiro, RJ: O instituto,

MADEIRA, Felícia R. Os jovens e as mudanças estruturais na década de 70: questionando pressupostos e sugerindo pistas. Cadernos de Pesquisa. São Paulo, no. 58, aug. 1986, p.15-48.
}

MAIA, A. A. R. M.; MANCEBO, D. Juventude, trabalho e projetos de vida: ninguém pode ficar parado. Psicologia: Ciência e Profissão, Brasília, v. 30, n. 2, p. 376-389, 2010.

NOVAES, Regina. Juventude e Sociedade: Jogos de espelhos. Sentimentos, percepções e demandas por direitos e políticas públicas. Revista Sociologia Especial - Ciência e Vida. São Paulo, outubro de 2007.

PAIS, José Machado. Ganchos, tachos e biscates: jovens, trabalho e futuro. Porto: AMBAR, 2001.

PESQUISA AGENDA JUVENTUDE BRASIL. Disponível em: <http://polis.org.br/publicacoes/107592/>. 2013

PESQUISA PERFIL DA JUVENTUDE BRASILEIRA. Disponível em: < http://novo.fpabramo.org.br/uploads/perfil_juventude_brasileira.pdf>. 2013

POCHMANN, M. (2004). Juventude em busca de novos caminhos no Brasil. In: NOVAES, R. e VANUCCHI, P. (orgs.) (2004). Juventude e sociedade: trabalho, educação, cultura e participação. São Paulo: Editora Fundação Perseu Abramo, p. 217-241.

SENNETT, Richard. A corrosão do caráter. as conseqüências pessoais do trabalho no novo capitalismo. Rio de Janeiro: Record, 1999. 204p.

SPOSITO, M. P. Algumas reflexões e muitas indagações sobre as relações entre juventude e escola no Brasil. In: ABRAMO, H. W.; BRANCO, P. P. M. (Org.). Retratos da juventude brasileira. São Paulo: Fundação Perseu Abramo, 2005. p. 87- 127. 
REGO, N.R.P

TAVARES, M. da C.; ASSIS, J. C. de. O grande salto para o caos - a economia política e a política econômica do regime autoritário Rio de Janeiro: Zahar, 1985.

TELLES, V. e CABANES, R. Nas tramas da cidade. São Paulo: Humanitas, 2006.

VIEIRA, Monica. Trabalho, qualificação e a construção social de identidades profissionais nas organizações públicas de saúde. Trab. educ. saúde [online]. 2007, vol.5, n.2, pp.271-286. ISSN 19817746.

WAISELFISZ, J. J. Mapa da Violência: os Jovens do Brasil. Brasília: Ritla, Instituto Sangari, Ministério da Justiça, 2013.

WALLERSTEIN, Immanuel. O Universalismo europeu. In: A retórica do poder. Trad. Beatriz Medina. São Paulo: Boitempo, 2007

WHYTE, William Foote. 2005 [1943]. Sociedade de esquina. Rio de Janeiro: Jorge Zahar Editor. 390pp.

Noelia Rodrigues Pereira Rego: Socióloga, doutoranda em Educação e Políticas Públicas pela Universidade Federal do Estado do Rio de Janeiro (UNIRIO), onde possui mestrado na mesma área, na linha de pesquisa educação (EJA), juventude e políticas públicas. É Professora pelo NEAd - PUC-Rio em Educação de Jovens e Adultos. Membro-fundadora do CEPL - Coletivo de Educação Popular e Libertária. É ainda consultora de EJA pela Secretaria Municipal de Educação do Município de Angra dos Reis - Rio de Janeiro.

E-mail: noeliarpr@hotmail.com 